\title{
Separability of Dominant Crop Cultures in Southern Germany Using TerraSAR-X Data
}

\author{
Kuria Thiong'o1, René Pasternak², Alfred Kleusberg'2, Frank Thonfeld1', Gunter Menz ${ }^{1,3}$ \\ ${ }^{1}$ Department of Geography, Bonn University, Bonn, Germany \\ ${ }^{2}$ Institute of Navigation, Stuttgart University, Stuttgart, Germany \\ ${ }^{3}$ Center for Remote Sensing of Land Surfaces, Bonn University, Bonn, Germany \\ Email: tbkuria@yahoo.com
}

Received 16 April 2015; accepted 30 May 2015; published 2 June 2015

Copyright (C) 2015 by authors and Scientific Research Publishing Inc.

This work is licensed under the Creative Commons Attribution International License (CC BY).

http://creativecommons.org/licenses/by/4.0/

(c) () Open Access

\section{Abstract}

The research aims at differentiating dominant crop cultures in two test sites of Baden-Wuerttemberg, Southern Germany by creating crop signatures from radar backscatter values. It seeks to establish whether the crop signatures collected in one test site are comparable or transferable to another test site. The two test sites are located in different agro-ecological zones as described in the climate maps of the "Klimaatlas Baden-Wuerttemberg". TerraSAR-X images (VV polarization) for the months of July and August $\mathbf{2 0 1 0}$ were overlaid with crop fields' ground truth data. As preprocessing steps, radiometric correction was carried out on the images in order to normalize the topographical effects. Classification of the crops was performed on a field scale, according to the mean and standard deviation of their backscatter values. From the results, potatoes could be uniquely differentiated from the cereals in the two different test sites for both the months of July and August 2010. Cereals (rapes, maize, barley, wheat and oats) had comparable backscatter values and their differentiation varied from one test site to another. The results' accuracy obtained with a maximum kappa coefficient of 0.82 agrees with results of a similar research carried out in North East Germany.

\section{Keywords}

TerraSAR-X, Radar Backscatter, Crop Signatures, Crop Differentiation

\section{Introduction}

Earlier studies have successfully used both active and passive sensors to classify and differentiate crop cultures in different areas [1]-[3]. These studies employ the use of the classical classification methods like the maximum 
likelihood algorithm which are restrictive since training data have to be collected to create specific spectral signatures for a given area of study. The classes obtained were thus restricted to a particular area with no spatial or temporal transferability possibilities [4]. In their study, however, Waske and Braun established that temporal and spatial classification parameters were transferable from one year to the next [5]. Optical sensors are affected by cloud cover and haze [6] [7] and hence the preference of radar data for crop classification, as it is independent of weather conditions [8]. Data can be collected all year round regardless of the existing weather conditions i.e. it is multi-temporal [3] [9] [10]. Possibilities of using TerraSAR-X for agriculture mapping have also been shown [11]. Field-based representation is the most appropriate for mapping agricultural land use in comparison to semi-natural areas because agricultural landscapes have a distinct parcel structure and with pure spectral responses in the core area away from the boundaries [12]. This, however, has a limitation in that it is heavily dependent on the field boundaries which need to be acquired prior to starting such classification and depending on the boundary acquisition time dataset collection; there may exist a mismatch among the datasets [13]. Whereas the use of single spatially high resolution TerraSAR-X images in a field-based classification method has a high potential for classifying specific land use types within an agricultural region at a detailed scale; the combination of images of two acquisition dates provides higher classification accuracy [14].

The need to establish a way of differentiating crop cultures more by their backscatter characteristics rather than just relying on the collected signatures motivated this study. The objectives of the study were therefore 1) to establish some of the important crop cultures common in the two test sites, 2) to differentiate crop cultures using their specific backscatter values, and 3) to create classification signatures for the important crop cultures in the area of study independent of the classical classification methods.

\section{Study Area}

Figure 1 below shows the geographic location of the test sites in Southern Germany with respect to the administrative regions. Since there can be a great variation in agricultural areas [15], test sites in different locations were considered. The Leingarten test site was located in the district of Heilbronn, in the administrative region of Stuttgart. The test site had the coordinates: $49.122^{\circ} \mathrm{N} 9.053^{\circ} \mathrm{E}, 49.122^{\circ} \mathrm{N} 9.183^{\circ} \mathrm{E}, 49.17^{\circ} \mathrm{N} 9.183^{\circ} \mathrm{E}$ and $49.17^{\circ} \mathrm{N}$

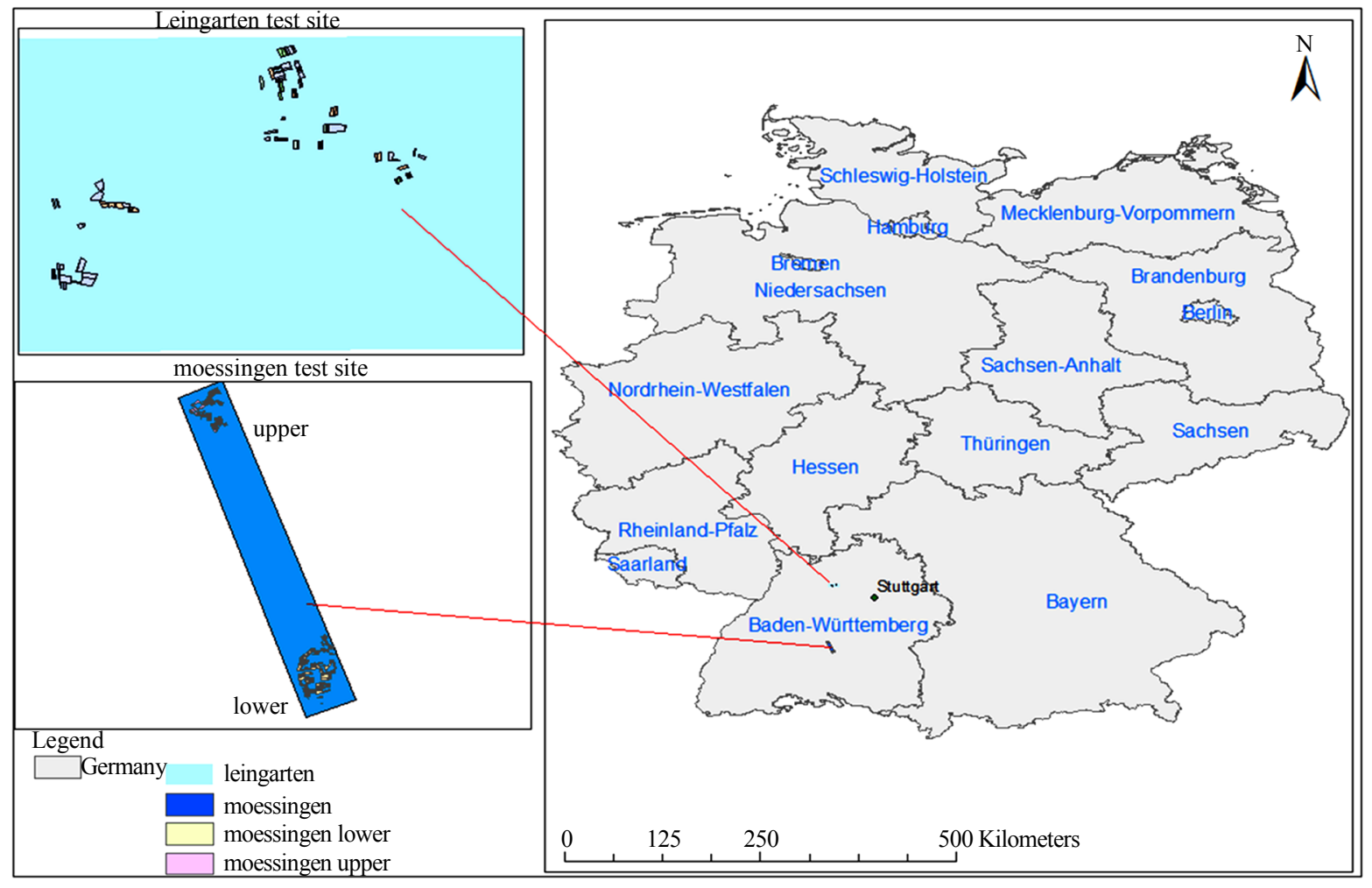

Figure 1. Locations of leingarten and moessingen test sites in Baden-Wuerttemberg (Germany). C Google earth 2015. 
$9.053^{\circ} \mathrm{E}$. These coordinates were given from the bottom left corner of the test site in an anticlockwise direction [16]. The average elevation of the test site was 200 meters asl. The Moessingen test site was located in the district of Tuebingen in the administrative region of Tuebingen, north of the Swabian Alb. The test site had the coordinates: $48.320^{\circ} \mathrm{N} 9.097^{\circ} \mathrm{E}, 48.327^{\circ} \mathrm{N} 9.125^{\circ} \mathrm{E}, 48.466^{\circ} \mathrm{N} 9.044^{\circ} \mathrm{E}$ and $48.458^{\circ} \mathrm{N} 9.016^{\circ} \mathrm{E}$. These coordinates were given from the bottom left corner of the test site in an anticlockwise direction. The coordinates are summarized in Table 1. The test site extended from North to South with an increase in altitude from an average of 450 meters asl in the North to an average of 800 meters asl in the South [17]. The change between these two altitude ranges was not gradual but was rather characterized by a sudden steep slope change. This test site was therefore subdivided into Moessingen upper test site and Moessingen lower test site. The test sites were selected according to the varying range of climatic and phenological aspects that characterize the state of Baden-Wuerttemberg and which have a direct influence on the growth and development of the crops at different stages and thus a direct influence on the amount of backscatter reflectance received from the surface. For example, considering the seeding time of oats, the seeds are sown earliest in the Leingarten test site, which is around the 16th of March and latest in the Moessingen test site, which is around the 15th of April [18].

\section{Data Sets and Methodology}

\subsection{Satellite Images}

TerraSAR-X satellite was launched on June 15, 2007 from Baikonur Cosmodrome in Kazakhstan. It has an altitude of $514 \mathrm{~km}$ and an inclination of $97.5^{\circ}$. Time for one orbit is 94.84 minutes and the orbit repetition time is 11 days with a radar carrier frequency of $9.65 \mathrm{GHz}$. It is a side-looking X-Band synthetic aperture radar (SAR) with a $3 \mathrm{~cm}$ wavelength that allows for stripmap, spotlight and scanSAR imaging modes with maximum spatial resolutions of 3 meters, 1 meter and 16 meters respectively. It uses both the single (VV, HH) and dual (VH, HV) polarization modes [19].

The images used in this study were TerrarSAR-X images acquired for the months of July and August, 2010 using the stripmap mode. They were right looking images, descending direction (D), VV-polarized and covered the strip number 006 . The look angle varied from $27^{\circ}$ to $30^{\circ}$. They were enhanced ellipsoid corrected (EEC) and spatially enhanced (SE), providing the highest possible square ground resolution [20] as it is shown in Table 2.

\subsection{Aerial Photographs}

The relevance of the aerial photographs acquired from the office of Geoinformation and Deployment, BadenWuerttemberg was to show the location of the land parcels in relation to other features like the forested areas, roads and the buildup areas. These were also overlaid with the digital cadastral maps for the purpose of verification and confirmation of the existing field boundaries. They were also in addition used to digitize the crop boundaries since during the field visits in 2010 , it was noted that some of the fields were under more than one crop type.

Table 1. Table showing the extent coordinates of the test sites.

\begin{tabular}{lcccc} 
& Bottom left corner & Bottom right corner & Top right corner & Top left corner \\
\hline Leingarten test site & $49.122^{\circ} \mathrm{N} / 9.053^{\circ} \mathrm{E}$ & $49.122^{\circ} \mathrm{N} / 9.183^{\circ} \mathrm{E}$ & $49.170^{\circ} \mathrm{N} / 9.183^{\circ} \mathrm{E}$ & $49.170^{\circ} \mathrm{N} / 9.053^{\circ} \mathrm{E}$ \\
Moessingen test site & $48.320^{\circ} \mathrm{N} / 9.097^{\circ} \mathrm{E}$ & $48.327^{\circ} \mathrm{N} / 9.125^{\circ} \mathrm{E}$ & $48.466^{\circ} \mathrm{N} / 9.044^{\circ} \mathrm{E}$ & $48.458^{\circ} \mathrm{N} / 9.016^{\circ} \mathrm{E}$ \\
\hline
\end{tabular}

Table 2. Information about the TerraSAR-X satellite images acquired for the study (SM = Stripmap; VV = VV-Polarization; $\mathrm{R}=$ Right Looking; EEC/SE = Enhanced Ellipsoid Corrected/Spatially Enhanced; D = Descending).

\begin{tabular}{cccc}
\hline & Leingarten & Leingarten & Moessingen \\
\hline Acquisition mode & SM/Strip_006VV "R" & SM/ Strip_006VV "R" & SM/Strip_006VV "R" \\
Product type & EEC/SE & EEC/SE & EEC/SE \\
Acquisition date & $10 / 07 / 2010$ & $01 / 08 / 2010$ & $10 / 07 / 2010$ \\
Orbit cycle; No.; dir & $102 / 17021 ; 154 ;$ "D" & $104 / 17355 ; 154 ; " \mathrm{D} "$ & $102 / 17021 ; 154 ; " \mathrm{D} "$ \\
\hline
\end{tabular}




\subsection{ALK Maps}

The Digital Cadastral Maps or "Automatisierte Liegenschaftskarte" (ALK) contained records of all the land parcels in the region and the information about where every parcel is located. This information was important especially in the selection of the test site. Test sites had to be selected in areas that were predominantly under agriculture in order to optimize on the results and research findings.

\subsection{Data Preparation}

Data preparation involves the following preprocessing steps as summarized in the work flow diagram (Figure 2).

The TerraSAR-X images acquired from German Aerospace Center (DLR) had been compressed into zip files to reduce their sizes and ease their workability. These zip files contained not only the images that were to be used but also their metadata. This metadata described inter alia the conditions like the local incidence angles that existed when the images were taken, calibration factor and the time when the images were taken. The original image was of type "continuous" and the data type was "unsigned 16-bit" with one layer. The information about the local incidence angle and on the location of radar shadowing and layover was derived from the geocoded incidence angle mask (GIM) image. When processing the GIM images, the data type was converted to "float" in order to allow for decimal numbers to be included in the operations [21]. The images were then subsetted in order

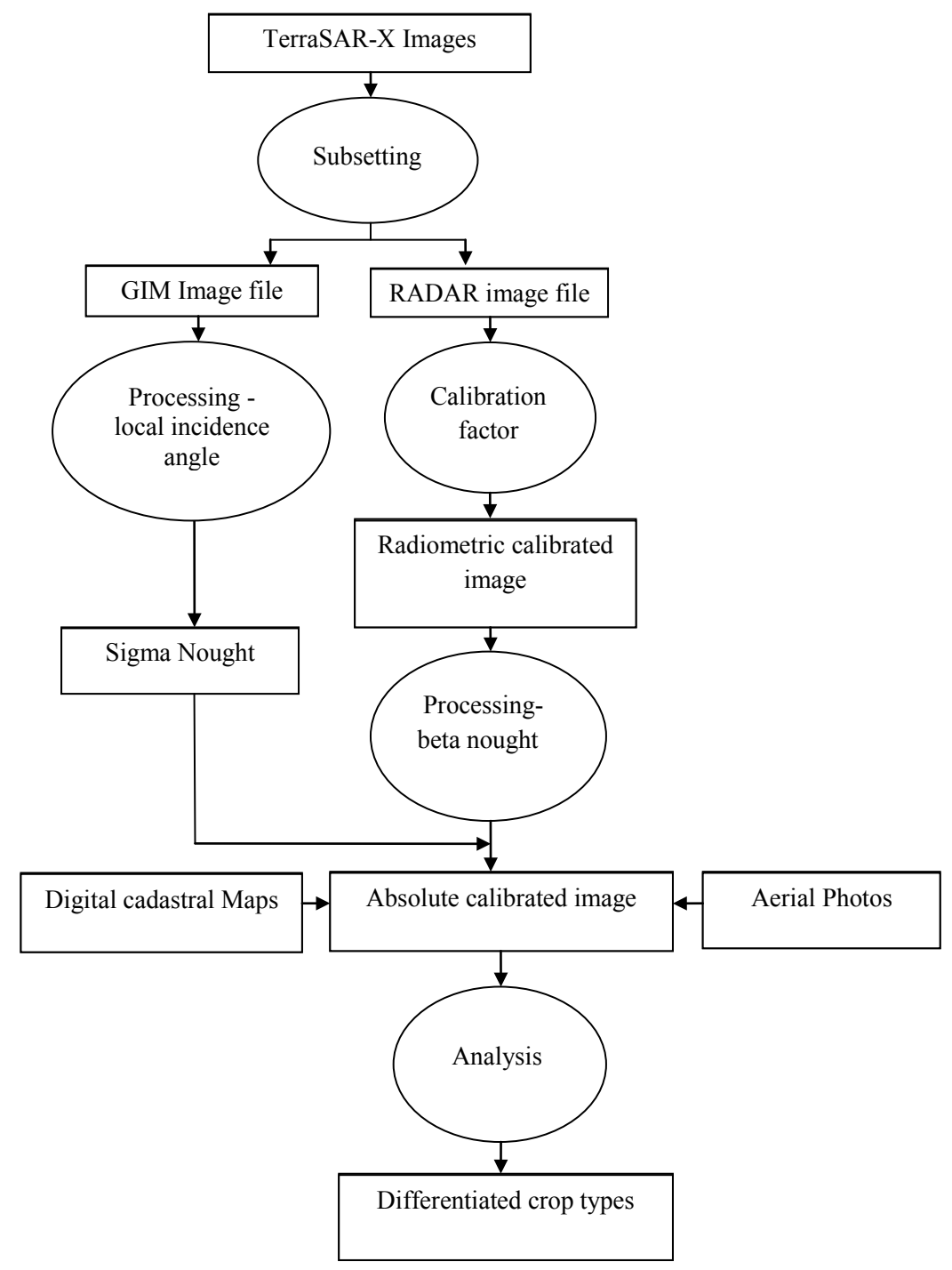

Figure 2. Pre-processing steps for the preparation of the TerraSAR-X images. 
to reduce the data size and the amount of time that would be required for pre- and processing. In order to ensure the clipping of the exact same area sizes and locations in the different images, an area of interest (AOI) template was used.

\subsection{Data Preprocessing and Processing}

Since for crops such as cereals TerraSAR-X images produce high values of separability even without filtering [14], no filter was applied as the images were already preprocessed (EEC and SC) from Table 2. Any extra speckle effect was assumed to be a crop surface characteristic. A radiometric calibration process had to be performed before they could be used for any further processing in order to minimize the incompatibility in images taken under different observation conditions like the incidence angles or even the ascending/descending mode by the different radar sensors [22]. The calibration factor was obtained from an xml file that came with the image data information. This factor depended on the image polarization. ERDAS Imagine (9.0) software was used for the processing of the images. Absolute calibration allowed taking into account all the contributions in the radiometric values that were not due to the target characteristics. This permitted to minimize the differences in the image radiometry and to make any TerraSAR-X images obtained from different incidence angles, ascending-descending geometries and/or opposite look directions comparable and even compatible to acquisitions made by other radar sensors. This was done by the computation of Beta Naught and Sigma Naught [22].

The radar brightness or Beta Naught $\beta^{O}$ which represents the radar reflectivity per unit area in slant range was obtained by multiplying the calibration factor with the power of the digital numbers (integer pixel values) using Equation (1). This was then converted into decibel (dB) values using Equation (2).

$$
\begin{aligned}
& \beta^{O}=k_{s}^{*}|D N|^{2} \\
& \beta_{d B}^{O}=10 * \log _{10}\left(\beta^{O}\right)
\end{aligned}
$$

where:

$\beta^{O}=$ Beta Naught or radar brightness representing the radar reflectivity per unit area in slant range;

$\beta_{d B}^{O}=$ Beta Naught in decibels;

$D N=$ Digital numbers or image pixel values;

$k_{s}=$ Calibration factor.

For the Sigma Naught $\sigma^{O}$ (radar reflectivity per unit area in ground range), the local incidence angle (angle between the radar beam and the normal to the illuminated surface) was necessary since the backscatter from the crop culture was not only influenced by the relative orientation of the illuminated cell and the sensor, but also on the distance in range between them [19].

Information about the local incidence angle for each pixel of the geocoded SAR scene and about the presence of layover and shadow areas was provided by the GIM which was also delivered as a separate file in the image data delivery information [22]. Incidence angles were given as 16-bit integer values in tenths of degrees, e.g. $10.1^{\circ}$ corresponds to an integer value of 1010 . The last digit of this integer number is used to indicate shadow and/or layover areas as follows:

1) indicates layover (ex. 1011);

2) indicates shadow (ex. 1012);

3) indicates layover and shadow (ex. 1013).

Layover and Shadow (LS) information was extracted by applying the formula:

LS $=$ GIM mod 10 [20].

The incidence angle was derived from the Geocoded Incidence Angle Mask (GIM) using Equation (3) and the sigma naught computed using Equations (4)-(7) [23].

$$
\begin{aligned}
& \theta_{I O C}=\frac{(G I M-(\text { GIM } \bmod 10))}{100} \\
& \sigma^{O}=\left(k_{s} *|D N|^{2}-N E B N\right) * \sin \theta_{i o c} \\
& \sigma^{O}=\beta^{O} * \sin \theta_{i o c}-N E S Z
\end{aligned}
$$




$$
\begin{aligned}
& \sigma^{O}=\beta^{O} * \sin \theta_{i o c} \\
& \sigma^{O}=\beta_{d B}^{O}+10 * \log _{10}\left(\sin \theta_{i o c}\right)
\end{aligned}
$$

where:

$\sigma^{O}=$ Sigma Naught;

$\theta_{i o c}=$ local incidence angle;

$N E B N=$ Noise Equivalent Beta Naught;

$N E S Z=$ Noise Equivalent Sigma Zero;

$N E S Z=N E B N^{*} \sin \theta_{i o c}$.

The values for NESZ were specified between $-19 \mathrm{~dB}$ and $-26 \mathrm{~dB}$ and therefore its influence in this study was neglected as it was very minimal [24].

The backscatter values are crucially dependent on the phenological stage of the crops [25]. Ground truth information about the crop fields was therefore collected and stored in a GIS dataset. The attribute data that was collected included information about the land parcels and the crops on them. This included: the use of the parcel; the crop type in the land parcel; the BBCH-code; the height of the crops; the distance between the rows of the crops; the cultivation (winter crop or summer crop); the date of the field visit; any notable remarks; the parcel number; the shape length and area of the land parcels. A test site was chosen and on this test site one crop type selected using an attribute query. A buffer of 4 meters was then created from the edge of each field to keep each crop field as homogeneous as possible and to eliminate mixed or unreliable edge pixels in the statistics. The different layers of the test sites data, the land parcels data, the calibrated TerraSAR-X images and the aerial photos were stacked and statistically analyzed using the ArcGIS Software (9.3) from ESRI. The "zonal statistics as table" tool was used to output the end results as a table showing the statistical information of the crops in each of the 21 fields (see Table 3). Every land parcel had a unique identification number (value) whose area was calculated (area). The minimum (min), maximum (max) and range (range) of the backscatter values were then calculated. The mean backscatter values (mean) and their standard deviations (std) were then deduced. The mean values and standard deviations for each field were calculated in decibels (dB). The mean-mean (mean value for

\begin{tabular}{|c|c|c|c|c|c|c|c|c|c|}
\hline \multicolumn{10}{|c|}{ Attributes of zonal St_TG_LGTN_august_mais_buffer } \\
\hline Objectid* & Value & Count & Area & Min & Max & Range & Mean & Std & Sum \\
\hline 1 & 997 & 4552 & 7112.50 & -25.05 & 2.34 & 27.40 & -8.71 & 4.38 & -39625.24 \\
\hline 2 & 1366 & 308 & 481.25 & -22.81 & -1.49 & 21.32 & -9.21 & 3.76 & -2836.86 \\
\hline 3 & 1368 & 12,888 & 20137.50 & -35.60 & 1.92 & 37.52 & -9.30 & 4.24 & -119877.72 \\
\hline 4 & 1372 & 1339 & 2092.19 & -26.04 & -0.84 & 25.20 & -10.76 & 4.38 & -14410.48 \\
\hline 5 & 1373 & 423 & 660.94 & -29.28 & -2.87 & 26.40 & -12.36 & 4.22 & -5227.54 \\
\hline 6 & 1375 & 1935 & 3023.44 & -28.42 & 1.25 & 29.67 & -9.85 & 4.64 & -19052.41 \\
\hline 7 & 1422 & 12,633 & 19739.06 & -35.45 & 2.89 & 38.34 & -9.45 & 4.37 & -119435.25 \\
\hline 8 & 1443 & 1626 & 2540.63 & -28.41 & 2.91 & 31.32 & -8.56 & 4.34 & -13926.51 \\
\hline 9 & 2570 & 761 & 1189.06 & -25.90 & -0.75 & 25.16 & -9.93 & 4.53 & -7554.72 \\
\hline 10 & 2572 & 128 & 200 & -24.05 & -2.08 & 21.96 & -10.27 & 4.31 & -1314.55 \\
\hline 11 & 2573 & 1167 & 1823.44 & -26.63 & 1.33 & 27.96 & -10.67 & 4.75 & -12451.18 \\
\hline 12 & 2576 & 1229 & 1920.31 & -27.55 & -0.86 & 26.69 & -10.63 & 4.60 & -13061.47 \\
\hline 13 & 2577 & 685 & 1070.31 & -26.48 & -0.95 & 25.53 & -10.99 & 4.41 & -7526.60 \\
\hline 14 & 2581 & 3062 & 4784.38 & -34.29 & 1.20 & 35.49 & -9.71 & 4.32 & -29719.49 \\
\hline 15 & 3628 & 12,619 & 19717.19 & -29.78 & 2.87 & 32.65 & -9.22 & 4.39 & -116290.49 \\
\hline 16 & 3629 & 315 & 492.19 & -30.92 & -0.42 & 30.49 & -10.63 & 4.75 & -3349.03 \\
\hline 17 & 7520 & 759 & 1185.94 & -35.99 & 2.02 & 38.01 & -10.12 & 5.46 & -7684.45 \\
\hline 18 & 13,590 & 3157 & 4932.81 & -30.73 & 2.59 & 33.32 & -10.03 & 4.82 & -31658.73 \\
\hline 19 & 16,088 & 16,569 & 25889.06 & -32.66 & 1.24 & 33.90 & -9.71 & 4.34 & -160927.39 \\
\hline 20 & 16,089 & 11,383 & 17785.94 & -29.14 & 3.07 & 32.21 & -9.17 & 4.41 & -104401.32 \\
\hline 21 & 24656 & 2263 & 3535.94 & -25.42 & 1.96 & 27.38 & -9.33 & 4.42 & -21103.21 \\
\hline
\end{tabular}

\section{Table 3. Results of the zonal statistics from different crops after processing carried out for the Leingarten test site.}


all fields within a test site) and the mean standard deviations were then calculated in decibels (dB) for the crops in the test site. These gave an average value of one crop type in the crop fields within a test site. For example, in the leingarten test site, all maize fields were selected and the mean and standard deviation values calculated. These values of the means and standard deviations were then averaged to give the mean-mean and mean standard deviation values respectively.

\section{Results and Discussion}

\subsection{General Results}

The dominant crop types that were classified within the test sites were: winter barley, rape, summer barley, oat, maize, winter wheat, summer wheat and potatoes.

The results displayed in Table 4 show the mean backscatter values (in decibels, $\mathrm{dB}$ ) and their corresponding mean standard deviation values (in decibels, $\mathrm{dB}$ ) of six different crop cultures that were common in all the test sites in Leingarten and Moessingen.

\subsection{Leingarten Test Site}

From the results of the Leingarten test site in Figure 3, potatoes could be uniquely identified in July. Rape could not be identified from maize while barley could also not be differentiated from wheat and oat. Three (3) distinct groups of crop cultures could therefore be differentiated: potatoes; rape and maize; barley, wheat and oat.

For August, potatoes could be uniquely identified. Rape again could not be differentiated from maize while barley could again not be differentiated from wheat and oat. Again, three (3) distinct groups of crop cultures could be identified: Potatoes; Rape and Maize; Barley, Wheat and Oats.

There was a general increase in the mean-mean backscatter from July to August. The greatest increase could be identified for barley, oat and wheat with an increase in the mean-mean backscatter values of more than $4 \mathrm{~dB}$. Maize, rape and potatoes had a minor increase of less than $1.5 \mathrm{~dB}$. There was an increase in mean standard deviation for rape, a decrease for barley, oat and wheat, and no change could be determined for maize and potatoes (Table 4).

\subsection{Moessingen Upper Test Site}

From the Moessingen Upper test site (Figure 4), the oat, barley and wheat cultures could be differentiated from one another in July, but it was difficult to differentiate for the potatoes, maize and rape crop types. This means that four distinct groups could be formulated: potatoes, maize and rape; oat; barley; wheat.

Table 4. Mean backscatter values ( $\mathrm{m} /$ mean) and their mean standard deviations ( $\mathrm{m} / \mathrm{stdev})$ - both in (in decibels, $\mathrm{dB})$ - for 6 crop types in the two test sites of Leingarten and Moessingen.

\begin{tabular}{|c|c|c|c|c|c|c|c|c|}
\hline Test site & Month & Output values & Barley & Oat & Maize & Rape & Wheat & Potatoes \\
\hline \multirow{4}{*}{ Leingarten } & \multirow{2}{*}{ July } & $\mathrm{m} /$ mean & -11.5 & -10.5 & -9.7 & -10.1 & -10.7 & -7.5 \\
\hline & & $\mathrm{m} / \mathrm{stdev}$ & 4.3 & 4.2 & 4.4 & 4.5 & 4.4 & 4.3 \\
\hline & \multirow{2}{*}{ August } & $\mathrm{m} /$ mean & -15.8 & -16.1 & -11.2 & -10.6 & -16 & -7.4 \\
\hline & & $\mathrm{m} / \mathrm{stdev}$ & 4.4 & 4.5 & 4.4 & 4.4 & 4.5 & 4.3 \\
\hline \multirow{4}{*}{$\begin{array}{c}\text { Moessingen } \\
\text { upper }\end{array}$} & \multirow{2}{*}{ July } & $\mathrm{m} /$ mean & -10.8 & -12.8 & -9.4 & -9.5 & -12.0 & -10.7 \\
\hline & & $\mathrm{m} / \mathrm{stdev}$ & 4.3 & 4.5 & 4.5 & 4.3 & 4.3 & 4.7 \\
\hline & \multirow{2}{*}{ August } & $\mathrm{m} /$ mean & -13.1 & -12.3 & -10.3 & -10.4 & -14.3 & -9.9 \\
\hline & & $\mathrm{m} / \mathrm{stdev}$ & 4.4 & 4.4 & 4.5 & 4.4 & 4.3 & 4.7 \\
\hline \multirow{4}{*}{$\begin{array}{c}\text { Moessingen } \\
\text { lower }\end{array}$} & \multirow{2}{*}{ July } & $\mathrm{m} /$ mean & -14.2 & & -9.0 & -12.4 & -14.2 & -8.0 \\
\hline & & $\mathrm{m} / \mathrm{stdev}$ & 4.5 & & 4.5 & 4.5 & 4.5 & 5.0 \\
\hline & \multirow{2}{*}{ August } & $\mathrm{m} /$ mean & -16.6 & & -11.0 & -11.0 & -14.7 & -10.2 \\
\hline & & $\mathrm{m} / \mathrm{stdev}$ & 4.6 & & 4.4 & 4.4 & 4.5 & 4.6 \\
\hline
\end{tabular}




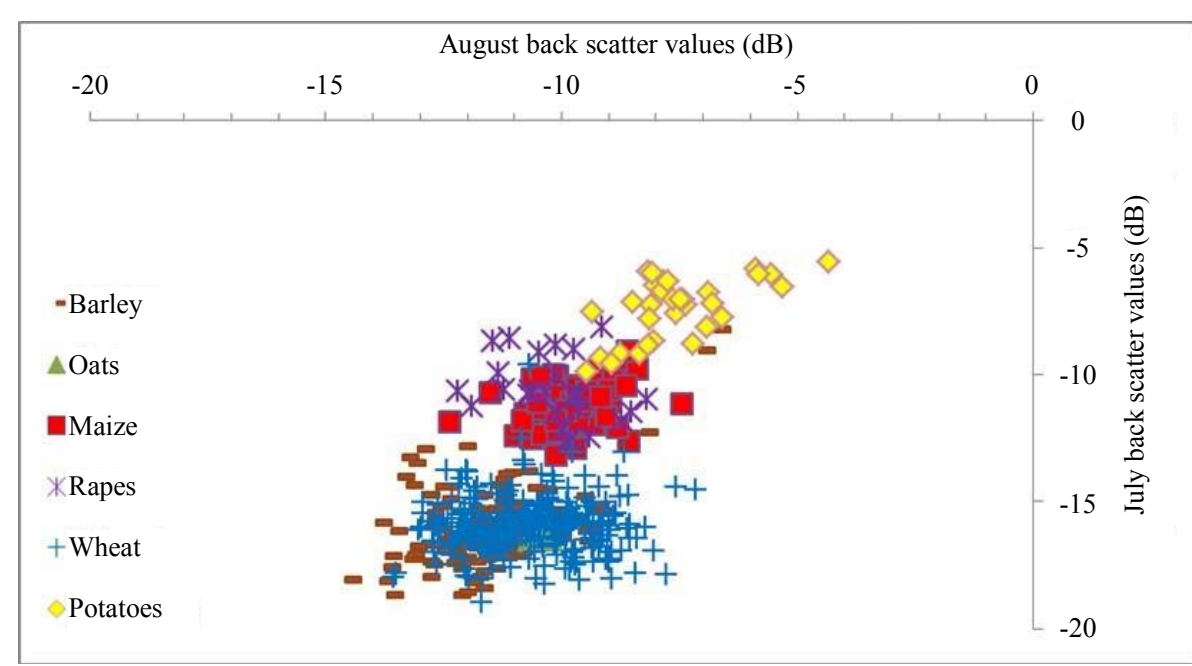

Figure 3. Mean back scatter values (in dB) for different crop types in Leingarten test site.

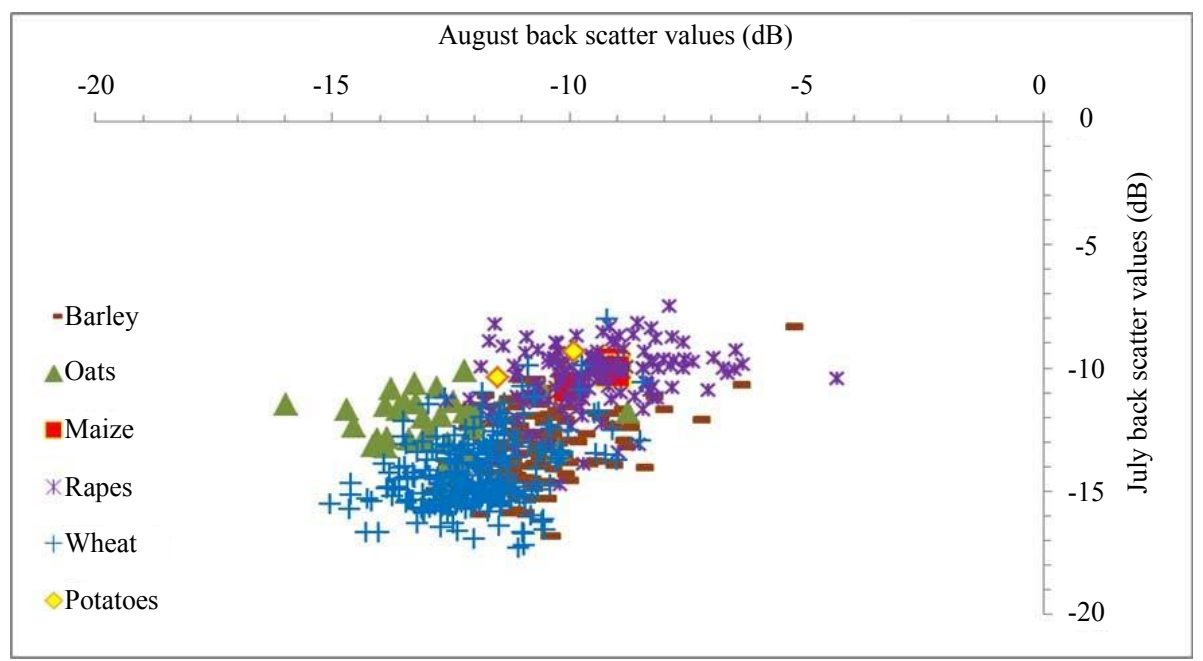

Figure 4. Mean backscatter values (in $\mathrm{dB}$ ) for different crop types in Moessingen upper test site.

For August the oat and wheat cultures could be well differentiated but in this month, it is difficult to differentiate potatoes from barley and maize from rape. The crop types could therefore be grouped into four clusters: maize and rape; potatoes and barley; oats; wheat. That means that for the two months only the maize and rape cultures could not be differentiated. There was also a general increase in mean-mean backscatter values from July to August except for oat and potatoes which showed a decrease (Table 4).

\subsection{Moessingen Lower Test Site}

As seen in Figure 5 for the Moessingen Lower test site, there were no fields containing oat. All crop types could be well differentiated apart from maize and rape for July. The occurring crop types could therefore be grouped into four clusters as: maize and rape; potatoes; wheat; barley. For the month of August, barley and wheat could not be differentiated while all the other crop types show different backscatter characteristics and could be differentiated. The four distinct groups that could be identified were: barley and wheat; potatoes; maize; rape. This means that in the two months all the crops within the test site could be differentiated from each other. A general increase of mean-mean from July to August except for rape where there was a decrease of $1.4 \mathrm{~dB}$, could be determined. The greatest change was in barley, maize and potatoes with an increase of over $2.0 \mathrm{~dB}$, while wheat shows with a minor increase of $0.5 \mathrm{~dB}$. The July mean standard deviation was $4.4 \mathrm{~dB}$ for maize and rape, $4.5 \mathrm{~dB}$ 
for wheat and $4.6 \mathrm{~dB}$ for barley and potatoes. The August mean standard deviation was $4.5 \mathrm{~dB}$ for barley, maize, rape and wheat and $5.0 \mathrm{~dB}$ for potatoes. In total there was an increase in mean standard deviation for maize, rape and potatoes, a decrease for barley and no change for wheat (Table 4).

\section{Summary and Conclusions}

To assess the accuracy of the separability for the different crop types, the kappa coefficient was applied. Using the ground truth data collected during the field work, the fields were divided into two sub-samples: one subsample was used for training of the classification while the complementary second sub-sample was used for the accuracy assessment. A kappa coefficient value of $82 \%$ was realized. As a further plausibility check of our findings, we compared them with the results of a study that had been carried out in Fuhrberg area, North East of Hannover, Germany [26], where backscatter values were also used to differentiate the different crop cultures. In the latter study, however, a multi-temporal filter (DeGrandi filter) was applied and the cultivation practices of the farmers were recorded. The average values acquired are highlighted in orange color in Table 5. These values

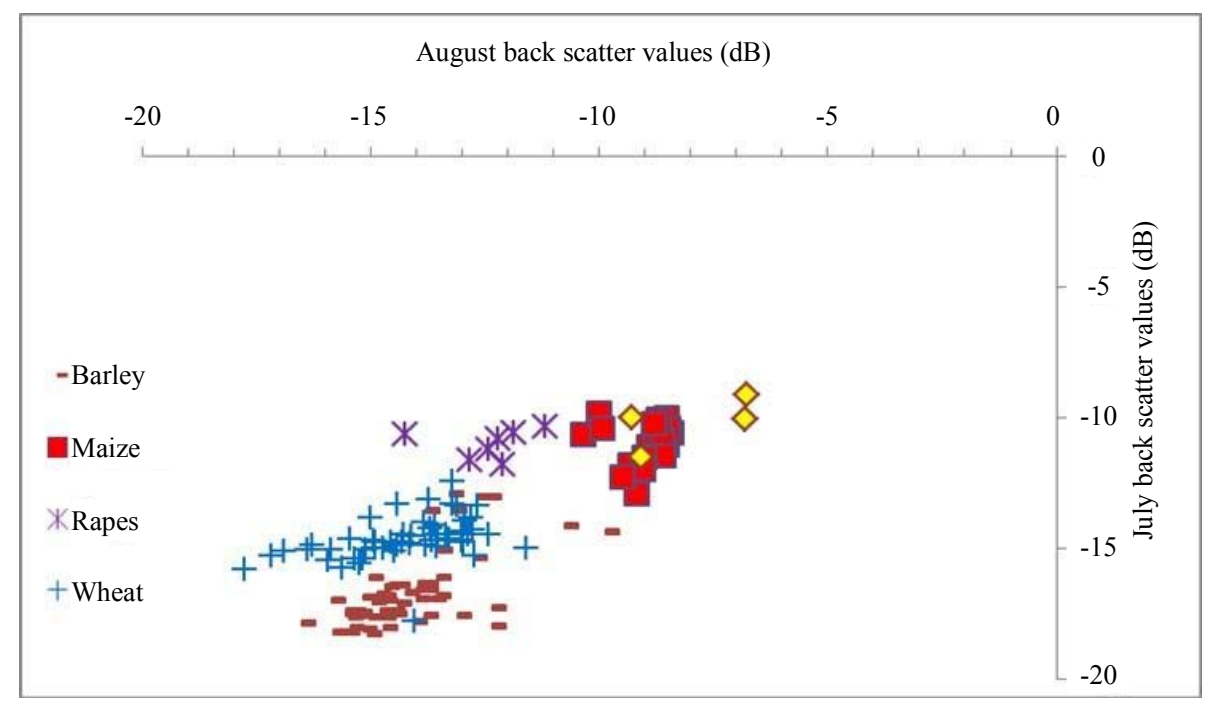

Figure 5. Mean backscatter values (in dB) for different crop types in Moessingen lower test site.

Table 5. Comparison of the realized mean backscatter values from the study with those of a previous study (reference values) carried out in the Fuhrberg area, North East of Hannover, Germany. The shaded cells are the values for July which had been deemed unreliable [26].

\begin{tabular}{ccc}
\hline Test site & July 2010 & August 2010 \\
Leingarten & Potatoes & Potatoes \\
& Rape, maize & Rape, maize \\
Boessingen upper & Potatoes, maize, rape & Barley, wheat, oat \\
& Oat & Maize, rape \\
& Barley & Potatoes, barley \\
Moessingen lower & Wheat & Oat \\
& Maize, rape & Wheat \\
& Potatoes & Barley, wheat \\
& Wheat & Potatoes \\
\end{tabular}


Table 6. Clustering of the different crop types according to their mean backscatter values, derived from TerraSAR-X.

\begin{tabular}{|ccccccccc}
\hline \multicolumn{7}{|c}{ Comparison of July mean } & \multicolumn{7}{c}{ backscatter values with reference mean backscatter values } & \\
\hline & & Barley & Oat & Maize & Rape & Wheat & Potatoes \\
\hline Leingarten test site & July & -15.9 & -16.1 & -11.2 & -10.6 & -16 & -7.4 \\
\hline Moessingen upper test site & July & -13.1 & -12.3 & -10.3 & -10.4 & -14.3 & -9.9 \\
Moessingen lower test site & July & -16.6 & & -11.0 & -11.0 & -14.7 & -10.2 \\
Reference values & July & $-\mathbf{- 1 2}$ & $-\mathbf{- 1 2}$ & $\mathbf{- 8}$ & $\mathbf{- 1 0}$ & $\mathbf{- 1 4}$ & $\mathbf{- 8}$ \\
\hline
\end{tabular}

were compared with the unshaded values, which represented the reliable values that had been realized from the various test sites, while the shaded values represented the values for the month of August and the values for the month of July which had been deemed unreliable due to absence of ground truth information. The best accuracies were achieved in the classification of the oats, rape, wheat and potatoes. The mean backscatter values for the barley and maize showed an upper deviation from the reference values. This can be due to the fact that both maize and barley are cultivated for various purposes and the purpose for which the crops are intended impacts on the method of cultivation. The fact that the study in the Fuhrberg area applied a filter in the data processing could also probably explain the slight differences that existed in the mean backscatter values [27].

In order to improve the performance of crop separability by the means of the backscatter values, records of other parameters, like soil characteristic values, the moisture present on the surface of the leaves during the time of acquisition, the local weather condition during the time of acquisition, and the cultivation practices undertaken by the farmer e.g. tillage method, weeding method, and purposes for which the crop is been grown, should be taken into account. In some of the fields in our test sites, it was observed that some crops might have been harvested earlier than in others. An example is barley in the Leingarten test site or oat in the Moessingen upper test site. From the summary of the clustering of the different crop types in the two test sites (see Table 6), it could be observed that most of the crop types cultures had unique backscatter characteristics in the various test sites. From the clustering of the crop types based on their backscatter values, it provides evidence that indeed crop signatures are transferable from one test site to another.

\section{Acknowledgements}

We would like to thank the German Aerospace Center (DLR) for providing us with the TerraSAR-X images (proposal ID: LAN0697), the Office for Geoinformation and Deployment (LGL) of the State Baden-Wuerttemberg for providing the aerial photographs, the Landesamt Baden-Wuerttemberg for providing the Digital Cadastral Maps (ALK) and the Katholischer Akademischer Auslaender-Dienst (KAAD) in Bonn for the financial support during the course of the Master study.

\section{References}

[1] Burini, A., Putignano, C., Del Frate, F., Licciardi, G., Pratola, C., Schiavon, G. and Solimini, D. (2008) TerraSAR$\mathrm{X} / \mathrm{SPOT}-5$ Fused Images for Supervised Land Cover Classification. IEEE International Geoscience and Remote Sensing Symposium, IGARSS 2008, 5, 373-376.

[2] Löhnertz, M., Schlerf, M. and Seeling, S. (2006) Land Cover and Land Use: Description of Vegetation Cover during the Growth Period and Crop Classification with Multitemporal High Resolution SPOT Images. Proceeding of the European Association of Remote Sensing Laboratories (EARSeL) Special Interest Group, 2, 80-88.

[3] Sabour, S.T., Lohmann, P. and Soergel, U. (2008) Monitoring Agricultural Activities Using Multi-Temporal ASAR ENVISAT Data. International Archives of the Photogrammetry, Remote Sensing and Spatial Information Sciences, 37, 735-742.

[4] Bargiel, D. (2013) Capabilities of High Resolution Satellite Radar for the Detection of Semi-Natural Habitat Structures and Grasslands in Agricultural Landscapes. Ecological Informatics, 13, 9-16. http://dx.doi.org/10.1016/j.ecoinf.2012.10.004

[5] Waske, B. and Braun, M. (2009) Classifier Ensembles for Land Cover Mapping Using Multitemporal SAR Imagery. ISPRS Journal of Photogrammetry and Remote Sensing, 64, 450-457. http://dx.doi.org/10.1016/j.isprsiprs.2009.01.003 
[6] Castillejo-González, I.L., López-Granados, F., García-Ferrer, A., Peña-Barragán, J.M., Jurado-Expósito, M., de la Orden, M.S. and González-Audicana, M. (2009) Object- and Pixel-Based Analysis for Mapping Crops and Their AgroEnvironmental Associated Measures Using QuickBird Imagery. Computers and Electronics in Agriculture, 68, 207215. http://dx.doi.org/10.1016/j.compag.2009.06.004

[7] Devadas, R., Denham, R.J. and Pringle, M. (2012) Support Vector Machine Classification of Object-Based Data for Crop Mapping, Using Multi-Temporal Landsat Imagery. International Society for Photogrammetry and Remote Sensing, 39, 185-190. http://dx.doi.org/10.5194/isprsarchives-xxxix-b7-185-2012

[8] Woodhouse, H.I. (2006) Introduction to Microwave Remote Sensing. CRC Press, Boca Raton.

[9] Baghdadi, N., Boyer, N., Todoroff, P., El Hajj, M. and Bégué, A. (2009) Potential of SAR Sensors TerraSAR-X, ASAR/ENVISAT and PALSAR/ALOS for Monitoring Sugarcane Crops on Reunion Island. Remote Sensing of Environment, 113, 1724-1738. http://dx.doi.org/10.1016/j.rse.2009.04.005

[10] Mróz, M. and Mleczko, M. (2008) Potential of Terrasar-X StripMap Data in Early and Rapid Agricultural Crops Mapping. Proceedings of the 2008 MARS Annual Conference "Geomatics in support of the CAP", Ljubljana, 3-5 December 2008.

[11] Sonobe, R., Tani, H., Wang, X., Kobayashi, N., Kimura, A. and Shimamura, H. (2014) Application of Multi-Temporal TerraSAR-X Data to Map Winter Wheat Planted Areas in Hokkaido, Japan. Japan Agricultural Research Quarterly, 48, 465-470. http://dx.doi.org/10.6090/jarq.48.465

[12] Dean, A.M. and Smith, G.M. (2003) An Evaluation of Per-Parcel Land Cover Mapping Using Maximum Likelihood Class Probabilities. International Journal of Remote Sensing, 24, 2905-2920. http://dx.doi.org/10.1080/01431160210155910

[13] Wu, S., Silvánhyphen Cárdenas, J. and Wang, L. (2007) Per-Field Urban Land Use Classification Based on Tax Parcel Boundaries. International Journal of Remote Sensing, 28, 2777-2801. http://dx.doi.org/10.1080/01431160600981541

[14] Mahmoud, A., Elbialy, S., Pradhan, B. and Buchroithner, M. (2011) Field-Based Landcover Classification Using TerraSAR-X Texture Analysis. Advances in Space Research, 48, 799-805. http://dx.doi.org/10.1016/j.asr.2011.04.005

[15] Bargiel, D. and Herrmann, S. (2011) Multi-Temporal Land-Cover Classification of Agricultural Areas in Two European Regions with High Resolution Spotlight TerraSAR-X Data. Remote Sensing, 3, 859-877. http://dx.doi.org/10.3390/rs3050859

[16] "Google Earth", 2009.

[17] "Google Earth", 2015.

[18] (1954) Klima-Atlas von Baden-Württemberg. Bad Kissingen (Deutscher Wetterdienst), 1953. Pp. 37 ; 9 Figs, 75 Charts. $30 \mathrm{dm}$. Quarterly Journal of the Royal Meteorological Society, 80, 283. http://dx.doi.org/10.1002/qi.49708034428

[19] Eineder, M., Fritz, T., Mittermayer, J., Roth, A., Boerner, E. and Breit, H. (2008) TerraSAR-X Ground Segment, Basic Product Specification Document. DTIC Document.

[20] Airbus Defence and Space (2014) Radiometric Calibration of TerraSAR-X Data.

[21] Breit, H., Fritz, T., Balss, U., Lachaise, M., Niedermeier, A. and Vonavka, M. (2010) TerraSAR-X SAR Processing and Products. Institute of Electrical and Electronics Engineers, 48, 727-740.

[22] INFOTERRA (2008) Radiometric Calibration of TerraSAR-X Data.

[23] Uprety, P., Yamazaki, F. and Dell'Acqua, F. (2013) Damage Detection Using High-Resolution SAR Imagery in the 2009 L'Aquila, Italy, Earthquake. Earthquake Spectra, 29, 1521-1535. http://dx.doi.org/10.1193/060211EQS126M

[24] Fritz, T. and Werninghaus, R. (2007) TerraSAR-X Ground Segment Level 1b Product Format Specification. Clustert Applied Remote Sensing (CAF), German Aerospace Center (DLR). German Aerospace Center (DLR), Technical TX-GS-DD-3307.

[25] McNairn, H., Champagne, C., Shang, J., Holmstrom, D. and Reichert, G. (2009) Integration of Optical and Synthetic Aperture Radar (SAR) Imagery for Delivering Operational Annual Crop Inventories. ISPRS Journal of Photogrammetry and Remote Sensing, 64, 434-449. http://dx.doi.org/10.1016/j.isprsjprs.2008.07.006

[26] Bargiel, D., Herrmann, S., Sörgel, U. and Lohmann, P. (2010) Land Use Classification with High Resolution Satellite Radar for Estimating the Impacts of Land Use Change on the Quality of Ecosystem Services. Proceedings of the ISPRS TC VII Symposium-100 Years ISPRS, Vienna, 5-7 July 2010, 68-73.

[27] Mirzaee, S., Motagh, M., Arefi, H. and Nooryazdan, M. (2014) Classification of Agricultural Fields Using Time Series of Dual Polarimetry TerraSAR-X Images. The International Archives of the Photogrammetry, Remote Sensing and Spatial Information Sciences, XL-2/W3, 191-196. http://dx.doi.org/10.5194/isprsarchives-XL-2-W3-191-2014 